\title{
A STRUCTURAL MODEL OF \\ CENTRAL BANK OPERATIONS \\ AND BANK INTERMEDIATION
}




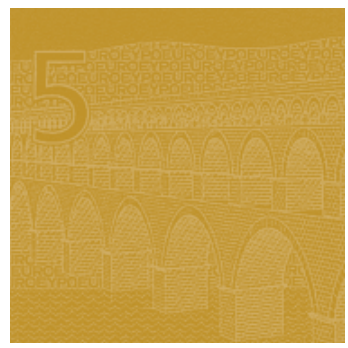

\title{
WORKING PAPER SERIES
}

NO I3I I MARCH 20II

\author{
A STRUCTURAL MODEL \\ OF CENTRAL BANK OPERATIONS \\ AND BANK INTERMEDIATION '
}

\author{
by Ulrich Bindseil ${ }^{2}$ \\ and Juliusz Jabłecki ${ }^{3}$
}

NOTE: This Working Paper should not be reported as representing the views of the European Central Bank (ECB).

The views expressed are those of the authors and do not necessarily reflect those of the ECB.

This paper can be downloaded without charge from http://www.ecb.europa.eu or from the Social Science Research Network electronic library at http://ssrn.com/abstract_id= 1781030.

I Views expressed in this paper are views of the authors, and not necessarily the ones of the respective central banks. We would like to thank our colleagues Frank Betz, Jérome Henry, Jean-Louis Schirmann, Leo von Thadden, Ralph Weidenfeller and in particular Philipp König from the

ECB for helpful discussions and relevant observations. We also thank participants of a seminar held in the ECB on 19 October 2010, as well as the editors of the ECB Working Paper Series for insightful comments. Special thanks go to an anonymous referee whose constructive suggestions were very useful in carrying out revision of the paper. 2 European Central Bank, Kaiserstrasse 29, D-603II Frankfurt am Main, Germany; email: ulrich.bindseil@ecb.europa.eu 
(C) European Central Bank, 2011

\section{Address}

Kaiserstrasse 29

60311 Frankfurt am Main, Germany

Postal address

Postfach 160319

60066 Frankfurt am Main, Germany

Telephone

+496913440

Internet

http://www.ecb.europa.eu

Fax

+496913446000

All rights reserved.

Any reproduction, publication and reprint in the form of a different publication, whether printed or produced electronically, in whole or in part, is permitted only with the explicit written authorisation of the ECB or the authors.

Information on all of the papers published in the ECB Working Paper Series can be found on the ECB's website, http://www. ecb.europa.eu/pub/scientific/wps/date/ html/index.en.html

ISSN 1725-2806 (online) 


\section{CONTENTS}

Abstract

Non technical summary

1 Introduction

6

2 Review of related literature and motivation

2.1 Optimal width of the standing facilities corridor

2.2 Merits of an active interbank market

2.3 Structural differences across banks and returns to scale of banking

2.4 The central bank as interbank intermediary and the length of the central bank balance sheet

3 The economic and financial sectors in the structural model

3.1 The household

3.2 The corporate

3.3 Two banks

3.4 The central bank

4 The equilibrium financial intermediation in the structural model

5 An example

6 Conclusions

Annex

References 


\begin{abstract}
The banking system is modeled in a closed system of financial accounts, whereby the equilibrium volume of bank intermediation between households and corporates reflects structural parameters such as household preferences, comparative cost structures of heterogeneous banks, loan demand of corporates, and the difference between the borrowing rate and the deposit facility rate of the central bank. The model also allows understanding the link between this difference (the width of the central bank standing facilities corridor) and the stance of monetary policy, and how this link changes during a financial crisis. It is shown how the narrowing of the standing facilities corridor can make more accommodating the stance of monetary policy in a financial crisis.
\end{abstract}




\section{Non technical summary}

One of the features of the recent crisis was the break-down of interbank markets which in most countries lie at the heart of the monetary transmission mechanism, as they facilitate the distribution of liquidity across the financial system and the determination of short- as well as longer-term interest rates. The flip side of money market dislocations was central bank "intermediation", i.e. simultaneous use by the banking system of central bank liquidity providing and absorbing operations. Though two-sided recourse to central bank liquidity facilities may occasionally occur even in normal times, largely due to market frictions, the fact that it happened in a persistent manner, in large scale, over a long period of time indicates that a more fundamental factor must have been at play.

The present paper provides a very simple and relevant intuition for why in a financial crisis such a sudden massive central bank intermediation is demanded by the banking system. The reasoning is based on a structural model of financial system represented by a closed set of financial accounts featuring households, corporates, the banking sector (represented by two banks) and the central bank. The equilibrium volume of bank intermediation between households and corporates is shown to reflect structural parameters such as household preferences, comparative cost structures of heterogeneous banks, loan demand of corporates, and the difference between the borrowing rate and the deposit facility rate of the central bank. Thus, the model captures the interaction between static differences of competitiveness within a heterogeneous banking system and the monetary policy implementation framework, yielding testable predictions regarding the effects of a financial crisis on interbank market activity and on the length of the central bank balance sheet.

In particular, the model predicts that in a financial crisis characterised by the break-down of interbank markets, the narrower the spread between the central bank borrowing and deposit rates: (i) the larger the central bank intermediation volume; (ii) the lower the interbank lending volume; (iii) the higher total intermediation between households and corporates through the financial system, and (iv) the lower the interest rates to be paid by corporates for obtaining loans. The latter two also mean that the narrower the corridor, the lower will be the contraction via financial intermediation triggered by a financial crisis. The structural model presented in this paper adds another powerful link between implementation technique and the stance of monetary policy, and how policy can react to this by using the width of the corridor and/or the length of the central bank balance sheet as an independent policy variable. 


\section{Introduction}

Monetary policy implementation is about steering the short end of the yield curve, which, together with adequate communication on future policies, impacts on medium and long-term interest rates via the expectations hypothesis of the term structure of interest rates. The question arises why central banks do not control short-term interest rates simply, transparently and effectively by committing to collect and to supply overnight funds at the relevant target interest rate, i.e. set a zero width overnight rate corridor through standing facilities. Instead, central banks (i) tend to supply central bank money through open market operations only from time to time (but on a regular basis) and partially using auction procedures with some rate and/or quantity uncertainty, and (ii) limit overnight rate volatility only partially through standing facilities at penalty rates, i.e. to set a non-zero corridor to overnight rates. This paper investigates why central banks seem to prefer the complicated and imperfect to a simple and fully effective approach to the control of short-term interest rates.

Under the current practice of most central banks, the rates of the standing facilities are often fixed at a "penalty level", i.e. such that the use of the facilities is normally not attractive relative to market rates. The interest rates on the two facilities then form the ceiling and the floor of a corridor within which short-term money market rates fluctuate. Such a corridor system is currently applied by the Bank of England, the ECB, The US Fed, and the central banks of Canada, Australia, and New Zealand among many others, with however large differences in the width of the corridor. For example, the Bank of Canada has applied over the last years a tight corridor of normally 50 basis points, with a temporary lowering to 25 basis points during the financial crisis. The Swedish Riksbank, uses a wider corridor of 100 bp (150 bp until June 2009), though it conducts also daily fine-tuning operations at a spread \pm 10 bp around the main policy rate, implying a de facto considerably narrower corridor. The ECB has set most of the time a corridor width of 200 basis points, with however a corridor of 50 basis points during a few weeks in January 1999 and some variations during the recent crisis. The UK applied for some years a 200 basis points corridor with however a 50 basis points corridor applying on each last day of a monthly reserve maintenance period. It generally narrowed down the width of its corridor to 50 basis points during the financial crisis. Also Hungary has applied mostly a 200 basis points corridor, but again with a temporary narrowing during the crisis. Finally, Poland set a constant 300 basis points corridor for the last years.

Besides contributing a new simple but powerful theory of the role of the central bank standing facilities corridor for the interbank market and the monetary policy stance, the paper also provides for the first time a clean representation of monetary policy implementation and bank intermediation in a closed system of financial accounts, allowing to understand better the nature and control of key central bank asset and liability items and overcome related misunderstandings (see e.g. Bindseil, 2004). 
Figure 1: Width of the standing facilities corridor in Canada, the euro area, Sweden, UK(*), Hungary and Poland (2004-2010).
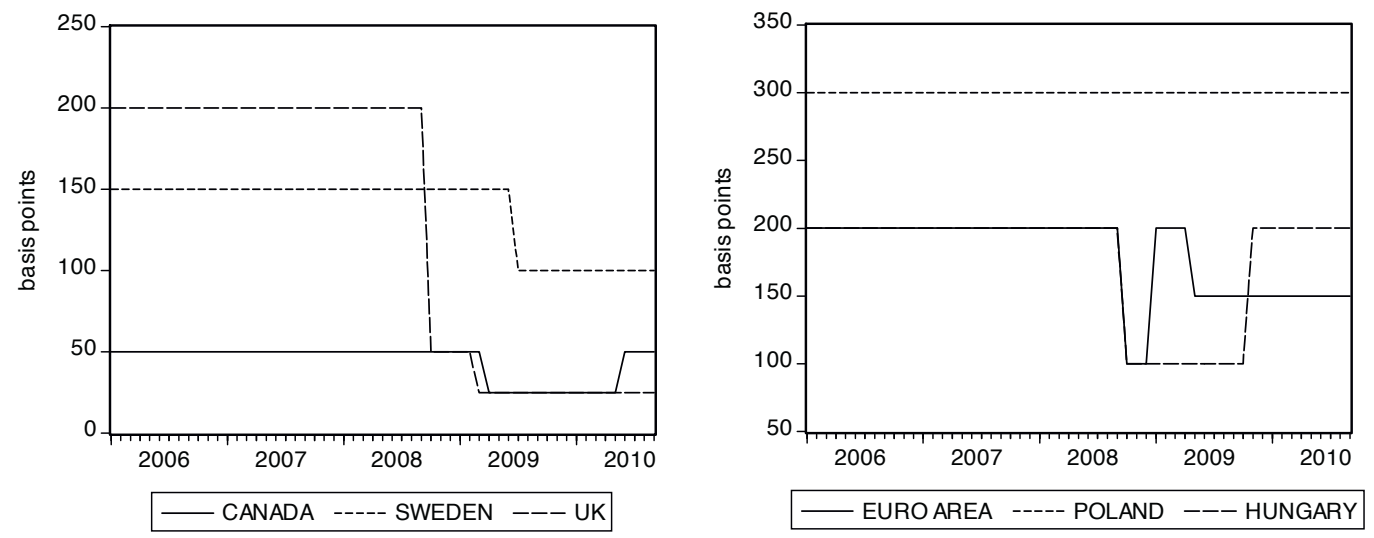

*)The Bank of England's wide corridor would be applied only within the reserve maintenance period, and on the final day of reserve maintenance period it would be narrowed to $50 \mathrm{bp}$.

The rest of the paper proceeds as follows. Section 2 surveys relevant literature and outlines the contribution of this paper. Section 3 presents the building blocks of the model. Next, section 4 derives the main conclusions of the model for different financial system environments. Section 5 presents a stylized simulation of the model. Finally, Section 6 concludes.

\section{Review of related literature and motivation}

\subsection{Optimal width of the standing facilities corridor}

The academic literature on the optimal width of the standing facilities corridor set by central banks is rather recent. Statements of central banks since the 1990s on the optimal width of the corridor are reviewed in Bindseil and Jablecki (2011), while for instance Woodford (2003), Bindseil (2004) or Whitesell (2006) discuss the general functioning of standing facilities corridors set by central banks.

One strand of literature explicitly asks the question about the optimal width of the interest rate corridor. Berentsen and Monnet (2008) are the first to propose a dynamic general equilibrium model of a channel system (i.e. a standing facilities corridor) with a welfare maximizing central bank, a money market, and commercial banks subject to idiosyncratic liquidity shocks. The key result of the model is that if the opportunity cost of holding collateral is positive, then it is optimal to apply a positive spread on standing facilities. Moreover, the paper yields the interesting result that a central bank has two equivalent options for implementing a given policy: it can either shift the corridor while keeping the spread constant, or it can 
change the spread. The latter result will be confirmed in the present, rather different model. In contrast, collateral scarcity and idiosyncratic liquidity shocks do not play any role in our model.

Berentsen, Marchesiani, and Waller (2010) explicitly ask if controlling the market interest rate is the objective, then why not set the spread to zero? Doing so allows the central bank to perfectly control the money market rate. The authors show in their model (which is again a general dynamic equilibrium with idiosyncratic liquidity shocks) that this is driven by fiscal ramifications associated with paying interest on deposits. If the central bank sets its target rate at the deposit rate, the central bank would actually need to make substantial interest payments. Without a portfolio of assets that generates a flow of income, the central bank must be able to either levy taxes or have the Treasury do so in order to make the interest payments. This power to finance interest payments on reserves may be limited for several reasons. If it is limited, the optimal corridor width is strictly positive. With the present's model focus on a closed system of financial accounts, the results of Berentsen et al seem difficult to replicate, since the central bank is structurally profitable regardless of any outright portfolio because of the non-remunerated monetary base its issues, and the remuneration of assets its hold. A lengthening of its balance sheet is income neutral (in the case of a zero corridor) or even increases central bank income (in the case of a positive spread).

Finally, Bindseil and Jablecki (2011) model the role of the width of the corridor for the turnover of the money market and the average length of the central bank balance sheet using a stochastic model of daily liquidity shocks within a closed system of financial accounts. While the present paper starts from a similar system of financial accounts, and also allows to explain the effects of the corridor on the size of interbank lending and the length of the central bank balance sheet it does not rely on any stochastic short-term shocks, but on structural differences between banks with regard to their deposit collection and lending technology.

\subsection{Merits of an active interbank market}

The second key strand of the literature focuses on the importance of an active interbank money market. Since the model will demonstrate (as other models have, in different ways) that the width of the standing facilities corridor is a key determinant of money market activity, it is crucial to understand the role of the interbank market to be able to conclude on the optimal width of the central bank standing facilities corridor.

Given that the overnight market for reserves is largely dominated by the central bank, Wiseman (2007) argues that it is debatable to what extent it actually shares the economic virtues of a market: "Under various assumptions, mostly true, a market discovers the price that maximizes the sum of the produces and consumer surpluses... Markets, therefore, have the effect of discovering the efficient price. But markets are not costless. For a bank to be a participant in this market will require two traders, at least two settlement 
staff, risk management people, auditors, and computers and space for all these people. In principle, this may be a price worth paying if the market discovered a price that maximized a surplus. But, of course, all this market paraphernalia is there to "discover" a price that is actually set by a committee. This is not even a real market: this is a pretend market, a Potemkin market - all appearance and no function."

Irrespective of the validity of Wiseman's argument, an interbank market may have another notable feature, brought up originally by Rochet and Tirole (1996), namely that interbank exposures generate incentives for banks to monitor one another's risks. The latter point is taken up by Hoerova and Monnet (2010) who also - similarly as in the present paper - raise the question why the standing facilities corridor is not set to zero, and "in other words, why do central banks enable the money market to exist?" Following Rochet and Tirole (1996), Hoerova and Monnet (2010) exlore the idea that the function of the money market is market discipline, and that money market induced discipline is an ex ante provision of incentives to banks to conduct business in a sage and sound manner.

The theoretical observation concerning disciplining effects of money market is well corroborated by the empirical research of Furfine (2001), King (2008) and Angelini, Nobili, and Picillo (2009) who document that, indeed, banks with worse risk profiles (characterized e.g. by high ratios of non-performing loans or low capital adequacy ratios) tend to pay higher rates on overnight funds than those with better risk profiles. If there were no market - as in a zero corridor regime - banks would transact only with the central bank which would reduce their risk awareness. Hence, even if the market for central bank reserves does not - as a market optimally should - discover the efficient price that maximizes the consumer and producer surpluses, it can still, according to those authors, fulfill an important economic function of facilitating a process of counterparty risk assessment and peer monitoring. One potential counterargument on this "monitoring" function of the interbank market, at least in the context of the issue of the optimal width of the interest rate corridor, is that sufficient other forms of interbank exposures would probably remain: securities holdings, longer term interbank lending and/or OTC derivatives. Moreover, the need to monitor counterparties in view of information asymmetries cannot be a purpose per se.

Bilateral exposures might potentially also be a channel through which a default of one bank spreads to other financial institutions, with significant negative welfare effects. Such contagious-prone feature of banks' linkages is modeled theoretically e.g. by Allen and Gale (2000) and Freixas, Parigi, and Rochet (2000) who show that the strength of the propagation mechanism will depend on the exact pattern of interbank exposures. Thus, the literature on interbank contagion - while in principle not opposed to active interbank markets as such - might weaken the argument on the economic merits of an active interbank market. 


\subsection{Structural differences across banks and returns to scale of banking activities}

The model proposed in the present paper derives an equilibrium level of financial intermediation in a closed system of financial accounts taking explicit assumptions on the cost functions of two banks behaving competitively. Banks intermediate between depositors and corporates, and the resulting intermediation depends explicitly on the efficiency of interbank intermediation either through interbank markets or through the central bank. Banks are assumed to behave competitively, and to have each specific increasing marginal costs of both deposit collection and corporate loan provision. Rochet and Tirole (1996) already noted the structural reasons for an interbank market (or central bank intermediation) in the form of cost differentials between banks in deposit collection and loan provision, which are also at the core of the present paper: "Some banks, perhaps due to their regional implantation, are good in collecting deposits, but have poor investment opportunities. In contrast, some other banks, such as the money centre banks, have plenty of such opportunities or else are sufficiently large to afford the large fixed costs associated with complex derivative or other high tech financial markets. It then seems natural for the former banks to lend to the latter." Structural comparative advantages between banks as discussed by Rochet and Tirole will drive in the present paper the interbank market and central bank intermediation.

Woodford (2010), discussing the general integration of financial intermediation into macroeconomic analysis, devotes particular attention to how the cost functions of the banking system drive the eventual extent of intermediation and the eventual spreads between deposit and loan rates - both being also explained in the current paper. In particular, Woodford (2010, 29-30) assumes, as we do, a "demand for intermediation schedule" and a corresponding "supply of intermediation service" function. The former is driven by the difference between the deposit supply and loan demand functions, while the volume of lending (and the spread) depends according to Woodford $(2010,29)$ on "the capacity of the financial sector to supply this [the intermediation] service at a margin low enough for the service to be demanded." Furthermore, Woodford (2010, 29-30) assumes that "intermediaries have costs of originating and servicing loans, or of managing their portfolios, such that in competitive equilibrium a spread will prevail that reflects the marginal cost of lending" and provides a number of reasons why marginal costs of loan provision should be increasing, such as natural expertise in only a limited market, capital constraints, etc. In the present paper, an intermediation supply function of the financial system is derived explicitly on the basis of simple marginal cost functions of competitive banks, whereby the role of the interbank market spreads and central bank facilities is taken into account as key factors in view of the comparative advantages of different banks as described above by Rochet and Tirole (1996). However, in contrast to Woodford (2010), the present paper assumes that deposit collection is also subject to increasing marginal costs. Indeed, shifts in the marginal costs of deposit collection for individual banks have certainly been a key driving force between much of the central bank 
intermediation observed in the last years (more than shifts in the marginal costs of loan provision). Goodfriend and McCallum (2007) also derive explicitly the spread between deposit and loan rates on the basis of assumptions on the production function for bank intermediation services, whereby, as Woodford (2010), they focus on the cost of loan provision (and not deposit collection). They assume a perfectly competitive banking system (as in the present model) but constant returns to scale.

\subsection{The central bank as interbank intermediary and the length of the central bank balance sheet}

Inspired by recent central bank practice, a literature has developed which studies in general the role of the central bank balance sheet length and composition as monetary policy instrument (see e.g. Cúrdia and Woodford, 2010). The present paper also studies one dimension of the length and composition of the central bank balance sheet as means of monetary policy. In the present model, the length of the central bank balance sheet, as driven by the width of the standing facilities corridor relative to the interbank market transaction costs, will have effects on the stance of monetary policy (although in a different way then in the model of Cúrdia and Woodford, 2010).

The present paper puts forward a variant of the argument espoused by Rochet and Tirole (1996) and Hoerova and Monnet (2010) stressing that if the overnight deposit market is substituted by central bank operations, then the length of the central bank balance sheet will increase markedly, and the central bank will need to monitor the risks inherent in the relevant exposures instead, even though there is no reason to expect that the central bank has a comparative advantage in counterparty monitoring and credit risk management probably the contrary. We believe the usefulness of having exposures being monitored in the interbank market is therefore a matter of comparative advantage, and not one relating to the usefulness of monitoring per se. Therefore, if the central bank takes over the intermediation role, the credit risk management for unsecured bank overnight exposures will either get poorer, with an implied higher likelihood of credit losses for society (and inferior projects getting more funding) or a higher total resource cost of credit risk management in society. The size of this potential phenomenon - the central bank becoming the credit risk manager of the economy - should not be underestimated. For instance, in August 2010, the total consolidated deposits with euro area monetary financial institutions ("MFIs") amounted to around EUR 10,300 billion, while total debt instruments issued (to the rest of the world) stood at EUR 2,900 billion. Eurosystem funding was around EUR 600 billion. Loans of banks to euro area residents stood at around EUR 12,000 billion. Finally, loans from MFIs to MFIs (according to the aggregate MFI balance sheet of the euro area MFIs) were around EUR 1,500 billion (all data from ECB Monthly bulletin, statistical annex). This gives an idea what potential 
Table 1: Example of potential lengthening of central bank balance sheet, two banks, euro area magnitudes in terms of banking system balance sheets (in billion of euro)

\begin{tabular}{|c|c|c|c|c|c|c|}
\hline & \multicolumn{2}{|c|}{ Pre-crisis } & \multicolumn{2}{|c|}{ Crisis component I $(*)$} & \multicolumn{2}{|c|}{ Crisis component $\mathrm{II}\left({ }^{* *}\right)$} \\
\hline \multicolumn{7}{|c|}{ Bank liabilities } \\
\hline & Bank 1 & Bank 2 & Bank 1 & Bank 2 & Bank 1 & Bank 2 \\
\hline Deposits and debt issued & 8,400 & 4,800 & 8,400 & 4,800 & 13,200 & 0 \\
\hline Central bank borrowing & 0 & 600 & 0 & 2,100 & 0 & 6,900 \\
\hline Interbank liabilities & 0 & 1,500 & 0 & 0 & 0 & 0 \\
\hline \multicolumn{7}{|c|}{ Bank assets } \\
\hline \multirow{3}{*}{$\begin{array}{c}\text { Loans to corporates } \\
\text { Interbank assets } \\
\text { Deposits with central } \\
\text { bank }\end{array}$} & 0 & 6,900 & 6,900 & 6,900 & 6,900 & 6,900 \\
\hline & 1,500 & 0 & 0 & 0 & 0 & 0 \\
\hline & 0 & 0 & 1,500 & 0 & 6,300 & 0 \\
\hline $\begin{array}{c}\text { Minimum length of CB } \\
\text { balance sheet }\end{array}$ & \multicolumn{2}{|c|}{600} & \multicolumn{2}{|c|}{2,100} & \multicolumn{2}{|c|}{6,900} \\
\hline
\end{tabular}

lengthening of the Eurosystem balance sheet could be experienced if the central bank no longer provides incentives to banks to balance their liquidity position in the market. A break-down in the interbank market combined with costless central bank intermediation could sweep the EUR 1,500 billion of interbank loans into the central bank balance sheet. Moreover, if some banks would discover, in particular during a financial crisis, to no longer be competitive in debt issuance and deposit collection, and if the collateral framework of the central bank is such as to accept large parts of bank assets, then the Eurosystem balance sheet could in principle lengthen even more substantially.

Suppose, by way of an illustration of the foregoing considerations, that we have a banking system with two banks, each of which provides loans of EUR 6,000 billion, and hence has to refinance this amount. On aggregate, EUR 13,200 billion is financed out of deposits and debt instruments, and EUR 600 billion from the central bank, and interbank credit is EUR 1,500 billion (to replicate the dimensions of the euro area MFI statistics). Total assets of banks, including loans, are EUR 13,800 (and assume that the rest of the consolidated balance sheet of the MFI sector is netted there). Table 1 explains how the central bank balance sheet lengthens if a financial crisis breaks out, whereby in a first step, interbank markets break down, and in a second step, all deposits previously held with Bank 2 shift to Bank 1. Again, such developments could be expected in particular if (i) central bank intermediation is costless, and (ii) the collateral framework is liberal in the sense that large parts of bank assets are accepted by the central bank (and with moderate haircuts). As is clear from the inspection of the table, the length of the central bank balance sheet increases under such circumstances by a factor of 10 , and the central bank thereby massively substitutes the market mechanism in terms of allocation of financial resources. In practice, it is difficult to assess how big a transfer of risk would be associated with such a lengthening of central bank balance sheet. Normally, as shown e.g. by Heinle and Koivu (2009), central banks aim at being exposed only to minimal ("residual") risk in their monetary 
Figure 2: "Intermediation" by the Eurosystem in the form of recourse to the deposit facility by the banking system, despite the banking system having a net liquidity deficit vis-a-vis the central bank, in million of euro, January 2008-September 2010

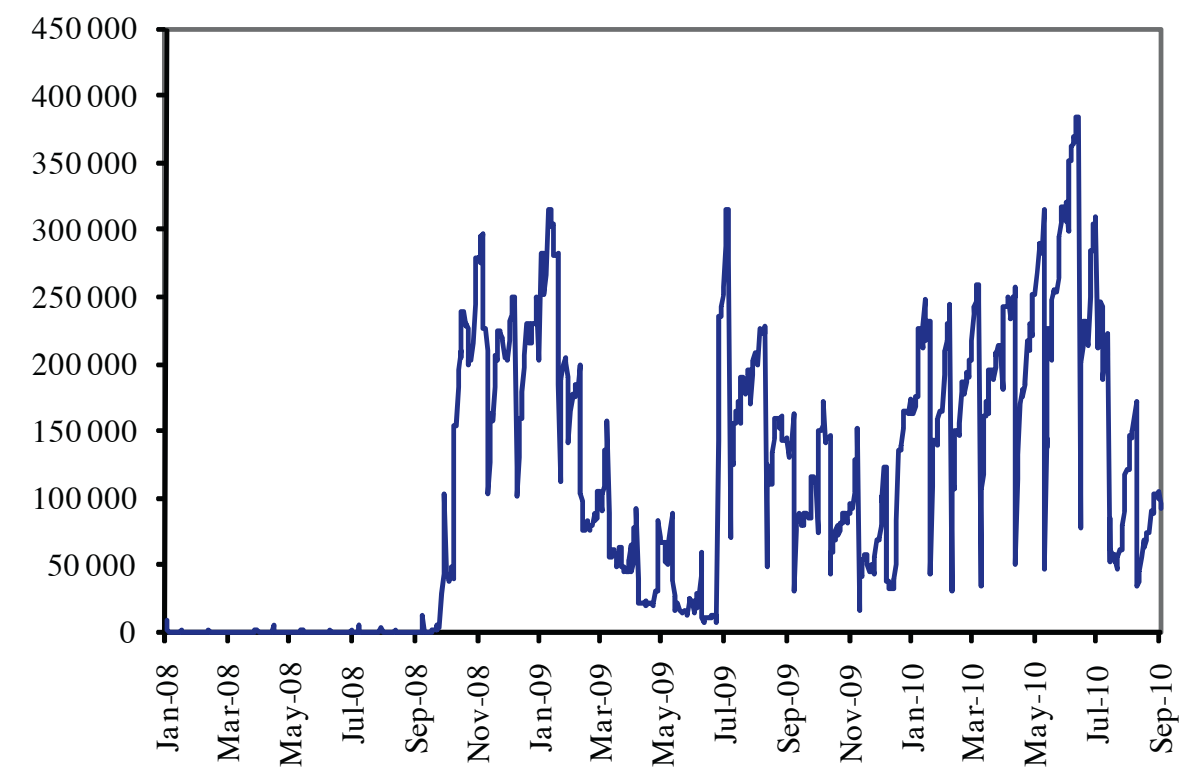

policy operations, as liquidity provision is usually collateralized and haircuts are imposed to protect central banks from significant adverse price changes. Still, typical risk measures would probably increase in such a case not only on account of skyrocketing total exposure, but also due to an increase in concentration and issuer-counterparty correlation as well as a fall in average credit rating of the collateral porfolio which would result from a necessary liberalization of the collateral framework (introduced to accommodate banking sector liquidity needs). Moreover, the scope for adverse selection phenomena (weaker banks with weaker collateral borrowing over-proportionally from the central bank) would be multiplied. Thus, central bank risk-taking would increase far more than proportionately. However, it is not only the bearing of increased risk, but also the need to actively manage those risks by devising and monitoring an effective risk mitigation framework - while having no comparative advantage over the market in that respect - that generates social costs. ${ }^{1}$ Ultimately, supporting this through a zero standing facilities corridor would mean denying the superiority of the market mechanism for the allocation of resources.

This paper will present a "structural" model of market- and central bank-based financial intermediation, which allows focusing on the eventual effects of the width of the standing facilities corridor on banks' deposit collection and loan provision, assuming heterogeneous commercial banks. The relevance of the innovative approach developed in our paper has been underlined by the behavior of banks during the current financial crisis. Indeed, during the financial crisis, central bank "intermediation", i.e. simultaneous use by the banking

\footnotetext{
${ }^{1}$ For more on the optimal conditions a collateral framework should satisfy see Bindseil and Papadia (2007).
} 
system of central bank liquidity providing and absorbing operations, became widespread. The following chart shows the recourse to the Eurosystem deposit facility, despite much larger recourse to liquidity providing facilities, such that the indicated time series shows the degree of central bank intermediation beyond the provision of funds necessary to cover the net funding needs of the banking system vis-a-vis the central bank.

Interestingly, the large scale intermediation by the Eurosystem starts only after the collapse of Lehman Brothers. While a part of this simultaneous recourse may be explained by the maturity transformation that the Eurosystem intermediation offered (liquidity providing operations up to a year conducted as so-called "fixed rate full allotment" operations in which counterparties always get the requested quantity, liquidity absorbing operations with overnight maturity), another part is explained by the fact that some banks with a large amount of illiquid assets, could no longer refinance sufficiently through retail deposit collection or capital market issuance. Moreover, cash-rich banks were unwilling to provide their excess funds to those banks under funding stress due to perceived credit risks, or prohibitive costs of managing these credit risks. The result was a simultaneous long-term recourse of the banking system to both liquidity providing and liquidity absorbing facilities. This two-sided recourse is obviously not related to daily liquidity shocks (as modeled in a stochastic setup such as e.g. in Bindseil and Jablecki, 2011) but to a long-term inability of some banks to find a cheaper way than central bank intermediation to address their funding issues - a feature that is explained in our present, "structural", modeling framework.

\section{The economic and financial sectors in the structural model}

The model assumes one household, one corporate, two banks and one central bank, and allows to derive effects of the corridor width decision of the central bank on (i) the volume of interbank activity; (ii) the length of the central bank balance sheet, (iii) retail deposit collection and lending to corporates; (iv) social welfare. The model is driven by the heterogeneity of banks in terms of deposit collection and corporate lending technology. At the same time, interbank transaction costs and other structural financial features of the economy matter. In this section the four types of economic agents are subsequently introduced.

\subsection{The household}

The household and the corporate both represent the real economy in the sense that they are the only agents in the model that hold real assets. At the outset, only the household holds real assets, namely equal to its 
equity, but then the household is assumed to diversify into financial assets: deposits with the two banks, and banknotes (Table 2). While the quantity of the latter is assumed to be fixed, the former is derived according to a simple preference function of the household. The household has no own preferences on how to distribute its deposit holdings with the two banks. Instead, the allocation will depend on the relative competitiveness of the deposit collection technologies of the two banks (see below).

When the household decides to hold financial assets instead of real assets, the real assets will end up with the corporate. Indeed, the corporate loan volume of the banking system will be equal to total deposits of households and banknotes (the latter is equal to the net lending of the central bank to the banks).

To keep the model as simple as possible, the deposit supply of the household is assumed to be proportional to the interest rate offered by banks ( $b$ being a positive constant):

$$
D^{S}=f^{S}(i)=b i
$$

Say that this reflects the opportunity costs of giving up real assets (beyond the ones given up to be able to hold banknotes). Inverted, one obtains the marginal valuation, or opportunity cost, curve of deposit holdings of the household: $i^{M V, D}=\frac{D}{b}$. Total deposits of households with banks are split up into deposits with the two banks, respectively, i.e. $D=D_{1}+D_{2}$, whereby the split up will be explained when presenting the banking system.

Table 2: Balance sheet of the household

\begin{tabular}{|cc|cc|}
\hline \multicolumn{3}{|c|}{ The household } \\
\hline Assets & $B$ & Liabilities \\
\hline Banknotes & $D_{1}$ & & \\
Deposits Bank 1 & $D_{2}$ & & \\
Deposits Bank 2 & $E-D_{1}-D_{2}-B$ & & \\
Real assets & Equity & \\
\hline
\end{tabular}

\subsection{The corporate}

The demand for loans by corporates is assumed to be analogously simple ( $R$ and $d$ being two positive constants):

$$
L^{D}=f^{D}(i)=R-d i
$$

Again, one may invert this to obtain a marginal valuation curve: $i^{M V, L}=\frac{R-L}{d}$, and also again, the total loan volume is split up into the two banks, whereby the split up will result from the relative competitive advantages of the two banks: $L=L_{1}+L_{2}$. 
Assuming for a moment that we would be in a ,zero transaction cost world" in which intermediation is costless - we could simply set demand equal supply to obtain: $i^{*}=\frac{R-B}{b+d}$ and $D^{*}=L^{*}-B=\frac{b(R-B)}{b+d}$. With positive intermediation costs, the outcome is slightly more complicated, and will be case dependent.

As the initial amount (value) of real assets in the economy is equal to the household equity $E$, and since this amount always remains the same, and since only households and the corporates will hold real assets, the real assets of the corporate $L_{1}+L_{2}$ will have to be equal to the households' financial assets, i.e. to $D_{1}+D_{2}+B$.

Table 3: Balance sheet of the corporate sector

\begin{tabular}{|cc|cc|}
\hline \multicolumn{3}{|c|}{ The corporate } \\
\hline \hline \multicolumn{3}{|c|}{ Assets } & \multicolumn{2}{c|}{ Liabilities } \\
\hline Real assets & $L_{1}+L_{2}$ & Bank loans & $L_{1}+L_{2}$ \\
\hline
\end{tabular}

\subsection{Two banks}

It is assumed that banks have (potentially) three types of assets: loans to corporates $(L)$, interbank loans $(Y)$, and deposits with the central bank $(C B D)$. They also have (potentially) three types of liabilities: deposits from households $(D)$; interbank liabilities $(Y)$; recourse to a central bank borrowing facility $(C B B$; the maturity of which is not relevant in the present model, i.e. it does not matter if we have in mind an overnight facility, or open market operations at a longer maturity applying the fixed rate full allotment procedure).

Financial intermediation is costly and it is assumed that banks incur costs both when collecting deposits and when granting loans. The marginal cost functions of the two banks differ and are given by: $c_{1}^{D}=$ $k_{1} D_{1} ; c_{2}^{D}=k_{2} D_{2} ; c_{1}^{L}=p_{1} L_{1} ; c_{2}^{L}=p_{2} L_{2}$, where $c_{j}^{D}$ is the marginal cost function of bank $j$ in collecting deposits, and $c_{j}^{L}$ is the marginal cost function of bank $j$ in providing loans to corporates, with $k_{j}, p_{j}(j=1,2)$ being positive constants.

Assuming fully competitive bank behavior, the deposit and loan provision volumes of the banks will maximise social welfare gains from financial intermediation. This assumes, in principle, that marginal costs of deposit collection and marginal costs of loan provision are in equilibrium equal across banks. This will however hold only under certain circumstances (see below).

Before bringing the central bank and the interbank market into the picture, the problem is thus to maximise social welfare by choosing $D_{1}, D_{2}, L_{1}, L_{2}$ (with $D_{1}=L_{1}$ and $D_{2}=L_{2}$, and $D_{1}, D_{2}, L_{1}, L_{2}>0$ ). The assumption of an interbank market allows to soften the constraint $D_{1}=L_{1}$ and $D_{2}=L_{2}$ into $D_{1}+D_{2}=$ $L_{1}+L_{2}$. At the same time, we need to make an assumption on interbank transaction costs, and deduct them 
Table 4: Balance sheet of Bank 1 and Bank 2

\begin{tabular}{|c|c|c|c|}
\hline \multicolumn{4}{|c|}{ Bank 1} \\
\hline \multicolumn{2}{|c|}{ Assets } & \multicolumn{2}{|c|}{ Liabilities } \\
\hline Loans to corporate & $L_{1}$ & Household's deposits & $D_{1}$ \\
\hline Interbank lending & $Y$ & Interbank borrowing & 0 \\
\hline CB deposit facility & $C B D_{1}$ & CB borrowing & $C B B_{1}$ \\
\hline \multicolumn{4}{|c|}{ Bank 2} \\
\hline \multicolumn{2}{|c|}{ Assets } & \multicolumn{2}{|c|}{ Liabilities } \\
\hline Loans to corporate & $L_{2}$ & Household's deposits & $D_{2}$ \\
\hline Interbank lending & 0 & Interbank borrowing & $Y$ \\
\hline CB deposit facility & $C B D_{2}$ & CB borrowing & $C B B_{2}$ \\
\hline
\end{tabular}

from total welfare gains. Call $Y$ the interbank lending volume from Bank 1 to Bank 2 (if Bank 2 is the net lender, then this number is negative). Assume that marginal interbank lending costs are constant, namely $u$. Hence, total costs of interbank trading will be $u Y^{2}{ }^{2}$

\subsection{The central bank}

The central bank issues banknotes, which are demanded by households, who can offer real assets in exchange. The demand of households for banknotes is assumed to be exogenous, as indeed, banknotes in circulation stayed relatively stable during the entire financial crisis 2007-2010. It is furthermore assumed that neither the central bank, nor the banks are interested in holding real assets. Therefore, real assets not held by the household will end up with corporates, to which banks lend.

The borrowing of banks from the central bank matching the amount of banknotes will further modify the constraints inherent in the balance sheets of the economic actors. In fact, if the banking system has a liquidity deficit vis-a-vis the central bank (and there is no deposit facility, or no reason to use it), then the constraint $D_{1}+D_{2}=L_{1}+L_{2}$ is now replaced by $D_{1}+D_{2}+C B B_{1}+C B B_{2}=L_{1}+L_{2}$ and $C B B_{1}+C B B_{2}=B$ is equal to banknotes in circulation $\left(C B B_{i}\right.$ is the borrowing of bank $i$ from the central bank). It is implied that loans are always equal to the sum of deposits collected and banknotes in circulation: $L=D+B$. If the central bank offers both a borrowing facility and a deposit facility, but at different rates, there can be cases, as we will see, of one bank depositing with the central bank and one borrowing from the central bank.

Of course the central bank will have operational costs as well, and these may increase with the amount lent to banks. Marginal costs of central bank lending may be assumed to be constant, while central bank deposit collection may be assumed to be costless. When lending, central banks need to manage their credit risk

\footnotetext{
${ }^{2}$ In the following system of financial accounts, for the sake of presentational simplicity, we assume that Bank 1 lends to Bank 2, if at all, and not the other way round. But of course a priori also Bank 2 could lend to Bank 1 . In view of positive transaction costs of interbank trading, it would never make sense to lend in both directions at once.
} 
Table 5: Central bank balance sheet

\begin{tabular}{|c|cc|}
\hline \multicolumn{2}{|c|}{ Central bank } \\
\hline Assets & \multicolumn{2}{c|}{ Liabilities } \\
\hline Borrowing of banks $C B B_{1}+C B B_{2}$ & $\begin{array}{c}\text { Banknotes } \\
\text { Deposit facility }\end{array}$ & $C B D_{1}+C B D_{2}$ \\
\hline
\end{tabular}

through close monitoring, establishing and implementing a collateral framework, and in taking discretionary risk control measures if necessary; when collecting deposits, central banks do not take credit risks, and do not need to compete for deposits as banks have to. What matters is that intermediation by the central bank is not costless. Specifically, we assume that while in normal times the marginal cost of central bank lending is likely to exceed market transaction costs (reflecting the lack of comparative advantage in risk management on the part of the central bank), in times of market stress both costs increase and additionally the relation between them is reverted, i.e. central bank intermediation becomes relatively competitive. Specifically, we assume that if $v$ is the constant marginal cost of central bank lending, then in normal times $v>u$, while in crisis times this is reverted with all costs increasing $v^{\text {crisis }}<u^{\text {crisis }}$. The spread $w$ ("width") between the two central bank facilities is to be distinct from these social costs of central bank intermediation. The spread will affect the actual behavior of banks, and will lead, strictly speaking, to a distortion, whenever it is not at the level of the marginal costs of intermediation by the central bank. This distortion will be zero in many cases, namely if the cost of interbank intermediation is anyway lower than the cost of central bank intermediation (which itself is below the width of the corridor), and no recourse to the central bank deposit facility takes place. From the perspective of the „society ex the central bank” the cost of the use of the central bank intermediation is given by: $\max \left(C B B_{1}+C B B_{2}, 0\right) w$.

The central bank balance sheet is schematically presented in Table 5.

Before considering now a number of key relevant cases, one may wonder about how the interest rate obtained relates to the central bank policy/lending rate. The assumption is that the demand and supply curves reflect expectations regarding inflation rates, and that interest rate policies of the central bank and real rates are consistent with these inflation expectations. In other words, we assume that the world is in equilibrium in terms of interest and inflation rates. Of course, it could be argued that e.g. changing the corridor may, if central bank intermediation is relevant, change the interest rate level and financial flows, and is likely to also trigger inflation or deflation dynamics. This could obviously be added to the present model, in which it will indeed be shown that loan rates will depend on the costs of financial intermediation, which itself will depend, at least in a financial crisis in which interbank markets break down, on the width of the corridor set by standing facilities, and hence the inter-bank intermediation offered by the central bank. 


\section{The equilibrium financial intermediation in the structural model}

The equilibrium financial intermediation, i.e. the level of deposits, loans, and respective interest rates (and hence the spread between the two) will be determined by the intersection of the gross demand curve for intermediation and the supply curve of such services. The gross demand curve is exogeneous to the financial sector, and rather simply established. We assume that loan demand is in any case strong enough to support some extent of intermediation including deposit collection from households. The gross rent from depositloan intermediation corresponds to the difference in the two marginal valuation curves: $i^{M V, L}-i^{M V, D}=$ $\frac{R-L}{d}-\frac{D}{b}=\frac{R-(D+B)}{d}-\frac{D}{b}=\frac{R-B}{d}-\frac{b+d}{d b} D$. The supply curve of intermediation services, i.e. the marginal cost curve of the (competitive) banking system taking into account the central bank issuance of banknotes and possible intermediation through standing facilities, is slightly more complex as we obtain a linear marginal cost curve with two kinks. The intermediation supply curve is characterized in the following proposition.

\section{Proposition 1. Financial intermediation supply schedule}

Let $c^{T, 0 \rightarrow K 1}(D), c^{T, K 1 \rightarrow K 2}(D)$, and $c^{T, K 2 \rightarrow \infty}(D)$ denote the three linear segments of the continuous total marginal cost curve, and $K 1=\left(D^{K 1}, c^{T, K 1}\right)$ and $K 2=\left(D^{K 2}, c^{T, K 2}\right)$, the Deposit - total marginal cost combinations characterizing the two kink points. Assume that Bank 1 has a comparative advantage (disadvantage) in deposit collection (loan provision) in the sense that $\frac{k_{1}}{p_{1}}<\frac{k_{2}}{p_{2}} \Leftrightarrow k_{1} p_{2}<k_{2} p_{1}$. Then, under the assumptions spelled out in the previous section, the aggregate banking system's marginal cost of intermediation services between the households and corporates is a continuous, monotonously increasing function in the total deposit volume intermediated, $c^{T}(D)$ ( $T$ for Total marginal cost) with three linear segments characterized as follows, and using the following notation:

From $D=0$ to the first kink point

$$
c^{T, 0 \rightarrow K 1}=\frac{p_{1} p_{2}}{p_{1}+p_{2}} B+\left(\frac{k_{1} k_{2}}{k_{1}+k_{2}}+\frac{p_{1} p_{2}}{p_{1}+p_{2}}\right) D
$$

Kink point 1 (K1) is characterized as follows

$$
K 1=\left(D^{K 1}, c^{T, K 1}\right)=\left(\frac{p_{2}\left(k_{1}+k_{2}\right)}{p_{1} k_{2}-p_{2} k_{1}} B, p_{2} k_{2} \frac{p_{1}+k_{1}}{p_{1} k_{2}-p_{2} k_{1}} B\right)
$$


From kink point 1 to kink point 2

$$
c^{T, K 1 \rightarrow K 2}=c^{T, K 1}+\frac{\left(k_{1}+p_{1}\right)\left(k_{2}+p_{2}\right)}{k_{1}+k_{2}+p_{1}+p_{2}}\left(D-D^{K 1}\right)
$$

Kink point 2 (K2) is characterized as follows

$$
K 2=\left(D^{K 2}, c^{T, K 2}\right)=\left(D^{K 1}+u \frac{k_{1}+p_{1}+k_{2}+p_{2}}{k_{2} p_{1}-k_{1} p_{2}}, c^{T, K 1}+u \frac{\left(k_{1}+p_{1}\right)\left(k_{2}+p_{2}\right)}{k_{2} p_{1}-k_{1} p_{2}}\right)
$$

After kink point 2

$$
c^{T, K 2 \rightarrow \infty}=c^{T, K 2}+\left(D-D^{K 2}\right)\left(\frac{k_{1} k_{2}}{k_{1}+k_{2}}+\frac{p_{1} p_{2}}{p_{1}+p_{2}}\right)
$$

Interbank trading will be:

$$
Y=\left(D-D^{K 2}\right)\left[\frac{k_{2}}{k_{1}+k_{2}}-\frac{p_{2}}{p_{1}+p_{2}}\right]
$$

Proposition 2. Under the assumptions taken, there exists a unique financial intermediation equilibrium determined by the intersection between the demand schedule for intermediation services $q(D)=\frac{R-B}{d}-\frac{b+d}{b d} D$ and the aggregate supply schedule as characterised in Proposition 1. The equilibirum fully characterises the financial accounts of the economy, i.e. including total household deposits with banks $D_{1}, D_{2}$, loan provision of banks to the corporate $L_{1}, L_{2}$, recourse to the central operations by the banks $C B D_{1}, C B D_{2} C B B_{1}$, $C B B_{2}$, household deposit rates $i^{D}$ and corporate loan rates $i^{L}$, and the extent of interbank intermediation (either in the form of an interbank market $Y$ or two sided recourse to central bank intermediation).

The propositions are derived in the annex. Figure 3 illustrates the three linear segments of the cost of intermediation curve. The slope of the first segment corresponds to the slope of the third one. The intermediate segment has a steeper slope. The intuition behind the three segments and the kink points is as follows.

First segment and first kink point: Comparative advantages of banks on both sides of their balance sheet can be fully reaped thanks to some costless interbank intermediation

In this segment, the comparative advantages of banks in deposit collection and loan provision can be fully realized in the sense that both types of marginal costs are in equilibrium equal across banks (i.e. $c_{1}^{D}=$ $\left.c_{2}^{D} ; c_{1}^{L}=c_{2}^{L}\right)$. The costless bridge between the banks that allows maintaining this condition until the first 
Figure 3: Demand of and supply for financial intermediation

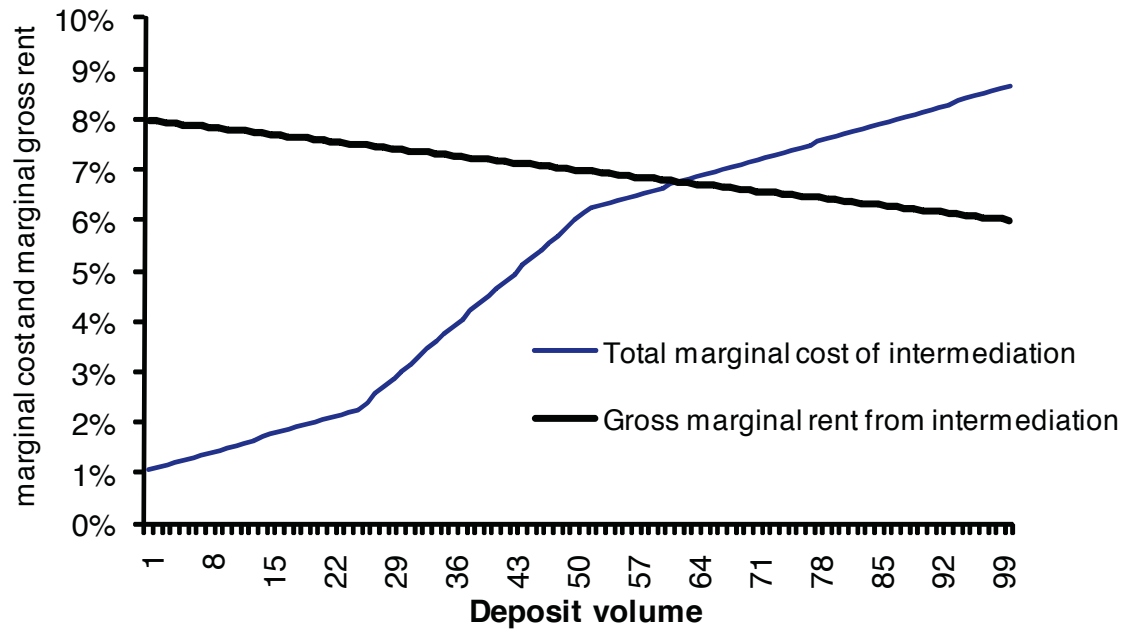

kink point is the allocation of central bank funding between the two banks, i.e. the two banks will share the central bank borrowing in such a way to maintain equality of marginal costs across banks on both sides of the balance sheets. This implies that the bank with a comparative advantage in deposit collection will borrow a lower share from the central bank than the one with comparative advantage in loan provision. It may be noted that if a costless interbank intermediation technology is available, then the total marginal cost curve of the provision of banking services continues as in the first segment and no kinks ever appear. Such a costless technology is either given by a perfectly efficient interbank market, or by a zero width interest rate corridor. The implied interbank lending volumes or the implied double-sided recourse to the two standing facilities can be easily calculated following the approach above for the splitting of the central bank borrowing.

Second segment and second kink point: Growing divergence of marginal cost until interbank intermediation sets in

Once the split up of the total liquidity deficit of the banking system vis-a-vis the central bank has been used up as bridge to ensure equality of marginal cost, the banking businesses of the two banks will grow for a while independently - and this makes up the second linear segment of the total marginal cost curve. Independent growth means that additional loans provided by Bank 1 are financed precisely by additional deposit collection of Bank 1, and additional loans extended by Bank 2 are financed precisely by additional deposits collected by Bank 2. This will lead immediately to a growing divergence of marginal costs across banks on both sides of their balance sheets and will continue until the difference in the marginal costs justifies interbank intermediation, which itself is not free of cost. For instance, bid ask spreads in the short term 
unsecured interbank market are at the order of magnitude of 5 to 10 basis points in normal times, and much higher in crisis times (and even prohibitive for many banks). Efficient extension of bank intermediation with two banks having to expand their business separately needs to follow the condition of equality of total marginal cost across banks. The split up of the total growth of bank intermediation needs to be inversely proportional to the marginal cost growth, such that total marginal costs stay equal across banks. Respecting this condition, the total marginal cost of intermediation grows from kink point 1 to kink point 2 as stated by Proposition 2.

Third segment: Growing interbank trading to keep the difference of marginal cost across banks equal to interbank intermediation costs

As shown in Annex 1, at kink point 2, defined in the proposition above, interbank trading sets in because the divergence of marginal costs across banks for the two banking activities are higher than transaction costs. The speed at which, beyond kink point 2, the five relevant variables (deposit collection of two banks, loan provision of two banks, and interbank trading) grow such as to minimize total marginal cost of bank intermediation is derived in Annex 1. Growth of the four activities (deposit collection and loan provision of each bank) will be again inversely proportional to the growth of marginal cost, and differences between marginal cost across banks will stay at the same level - namely marginal interbank intermediation costs (transaction costs). Total marginal cost of bank intermediation grows again at the speed of segment 1 of the intermediation supply curve.

\section{An example}

An example with six scenarios is now provided to illustrate the model and some of the effects that it allows to capture. Table 6 shows the parameters chosen, and the resulting financial accounts of the economy. Annex 2 in addition provides for the five scenarios the details of the intermediation supply function.

The six specifications chosen may be described briefly as follows. First, for all specifications, household equity, which is equal to the real assets in the economy, is 500, and banknotes in circulation, which is equal to the liquidity deficit of the banking system vis-a-vis the central bank is 100. Also the parameters of household supply of deposits, and of corporate demand for loans remain the same for all cases, namely $b=5000, R=500$, and $d=5000$. In all scenarios, Bank 1 has a comparative advantage over Bank 1 in deposit collection, or equivalently Bank 2 has a comparative advantage compared with Bank 1 in providing 
Table 6: A simulation of the model for six different specifications of parameters

\begin{tabular}{|c|c|c|c|c|c|c|}
\hline Scenario & $\mathrm{I}$ & II & III & IV & V & VI \\
\hline HH equity $E$ & 500 & 500 & 500 & 500 & 500 & 500 \\
\hline Banknote demand $B$ & 100 & 100 & 100 & 100 & 100 & 100 \\
\hline HH preference parameter $b$ & 5000 & 5000 & 5000 & 5000 & 5000 & 5000 \\
\hline Corporate technology paramater $R$ & 500 & 500 & 500 & 500 & 500 & 500 \\
\hline Corporate technology paramater $d$ & 5000 & 5000 & 5000 & 5000 & 5000 & 5000 \\
\hline marg cost depo coll B1 $k_{1}$ & $0,010 \%$ & $0,010 \%$ & $0,010 \%$ & $0,010 \%$ & $0,010 \%$ & $0,010 \%$ \\
\hline marg cost depo coll B2 $k_{2}$ & $0,010 \%$ & $0,010 \%$ & $0,200 \%$ & $0,010 \%$ & $0,200 \%$ & $0,200 \%$ \\
\hline marg cost loan prov B1 $p_{1}$ & $0,020 \%$ & $0,010 \%$ & $0,020 \%$ & $0,020 \%$ & $0,020 \%$ & $0,020 \%$ \\
\hline marg cost loan prov B2 $p_{2}$ & $0,005 \%$ & $0,005 \%$ & $0,005 \%$ & $0,005 \%$ & $0,005 \%$ & $0,005 \%$ \\
\hline Interbank TAC $u$ & $0,10 \%$ & $0,10 \%$ & $0,10 \%$ & $3,00 \%$ & $3,00 \%$ & $3,00 \%$ \\
\hline Width of corridor $w$ & $2,00 \%$ & $2,00 \%$ & $2,00 \%$ & $2,00 \%$ & $2,00 \%$ & $0,10 \%$ \\
\hline \multicolumn{7}{|c|}{ Output } \\
\hline Segment of intersection & 3 & 1 & 3 & 2 & 2 & 3 \\
\hline$D *$ & 154 & 159 & 141 & 153 & 120 & 141 \\
\hline$L *$ & 254 & 259 & 241 & 253 & 220 & 241 \\
\hline Loan-Depo spread & $1,8 \%$ & $1,3 \%$ & $2,4 \%$ & $1,9 \%$ & $3,2 \%$ & $2,4 \%$ \\
\hline \multicolumn{7}{|c|}{ Full balance sheet output } \\
\hline HH Assets Banknotes $B$ & 100 & 100 & 100 & 100 & 100 & 100 \\
\hline HH Assets Deposit Bank $1 D_{1}$ & 72 & 79 & 133 & 62 & 107 & 133 \\
\hline HH Assets Deposit Bank $2 D_{2}$ & 82 & 79 & 7 & 91 & 13 & 7 \\
\hline HH Real Asset $E-B-D_{1}-D_{2}$ & 246 & 241 & 259 & 247 & 280 & 259 \\
\hline HH Liabs Equity $E$ & 500 & 500 & 500 & 500 & 500 & 500 \\
\hline Bank 1 Assets Loans to Corp $L_{1}$ & 55 & 86 & 52 & 62 & 107 & 52 \\
\hline Bank 1 Assets Interbank lend $Y$ & 17 & 0 & 81 & 0 & 0 & 0 \\
\hline Bank 1 Assets deposits CB $C B D_{1}$ & 0 & 0 & 0 & 0 & 0 & 81 \\
\hline Bank 1 Liabs deposits HH $D_{1}$ & 72 & 79 & 133 & 62 & 107 & 133 \\
\hline Bank 1 Liabs borrow from $\mathrm{CB} C B B_{1}$ & 0 & 7 & 0 & 0 & 0 & 0 \\
\hline Bank 2 Assets Loans to Corp $L_{2}$ & 200 & 172 & 188 & 191 & 113 & 188 \\
\hline Bank 2 Liabs deposits $\mathrm{HH} D_{2}$ & 82 & 79 & 7 & 91 & 13 & 7 \\
\hline Bank 2 Liabs interb boddow $Y$ & 17 & 0 & 81 & 0 & 0 & 0 \\
\hline Bank 2 Liabs borrow from $\mathrm{CB} C B B_{2}$ & 100 & 93 & 100 & 100 & 100 & 181 \\
\hline Corporate Assets Real $L_{1}+L_{2}$ & 254 & 259 & 241 & 253 & 220 & 241 \\
\hline Corporate Liabs loan from Bank $1 L_{1}$ & 55 & 86 & 52 & 62 & 107 & 52 \\
\hline Corporate Liabs loan from Bank $2 L_{2}$ & 200 & 172 & 188 & 191 & 113 & 188 \\
\hline CB Assets lending Bank $1 C B B_{1}$ & 0 & 7 & 0 & 0 & 0 & 0 \\
\hline $\mathrm{CB}$ Assets lending Bank $2 C B B_{2}$ & 100 & 93 & 100 & 100 & 100 & 181 \\
\hline CB Liabs Banknotes $B$ & 100 & 100 & 100 & 100 & 100 & 100 \\
\hline CB Liabs Deposits Bank $1 C B D_{1}$ & 0 & 0 & 0 & 0 & 0 & 81 \\
\hline
\end{tabular}


loans, in the sense that $\frac{k_{1}}{p_{1}}<\frac{k_{2}}{p_{2}}$.

- Scenario I is the base case for all other scenarios. "normal" case, whereby Bank 2 has a comparative advantage in providing loans. Deposit collection costs are the same for the two banks. The banking system collects deposits of 154, and provides loans of 254. It charges a spread between deposit collection rates and corporate loan rates of 1.8\%. Total interbank trading is 17.1, i.e. Bank 1 lends to Bank 2 this amount, reflecting the higher productivity of Bank 2 in providing corporate loans. It is important to note that the recourse to interbank borrowing by Bank 2 is not out of weakness, but out of comparative advantages regarding asset side activities (of course, one could also have obtained interbank flows in the same direction by assuming that banks 1 and 2 are identical in terms of loan provision technology, but Bank 2 is less efficient in terms of deposit collection).

- Scenario II illustrates that the absence of an interbank market may be the result of too low relative difference in costs between the two banks in deposit collection and loan provision. Indeed, the only difference to specification $I$ is that the marginal cost of loan provision of Bank 1 is now half of the previous case (still the double of Bank 2). Interbank trading falls to zero, as the intersection between the marginal cost curve of financial intermediation and gross marginal gains from intermediation is in the second segment of the intermediation supply curve.

- Specifications III, IV, and V all illustrate financial crisis cases. Specification III reflects the case in which Bank 1 has e.g. a bad press and depositors have doubts on its solvency. The result is a sort of depositor run without dynamics, captured in the model by a strong increase (a multiplication by 20) of deposit collection costs. The result is a reduced volume of financial intermediation and higher depositloan rate spreads, but increasing interbank volumes. It should be noted that the reduced volume of financial intermediation is translated in the model to a smooth return of real assets to the household. As we know, financial crisis dynamics are more complex than that, and asset fire sales by corporates will be difficult. Instead, corporates could default for liquidity reasons.

- In specification IV, only interbank transaction costs increase relative to case I, namely by a factor of 30, surpassing the level of the typical width of the corridor of the central bank standing facilities (of central banks applying a wide corridor). This case thereby also illustrates the one in which interbank markets break down totally, and the central bank may take over the structural intermediation role between banks. However, in this scenario, interbank intermediation costs are in any case so high that there is no such intermediation, i.e. again, the intersection between the intermediation supply and demand curves is in the second segment of the latter. 
- Case $\mathrm{V}$ is the one of a full-blown financial crisis, in which both a "static" run on Bank 1 takes place, and interbank transaction costs increase dramatically. Total financial intermediation decreases further, and the spread between deposit rates and corporate loan rates increases to a new record level. If indeed it is the central bank which took over the interbank intermediation role, then the width of the corridor is now directly decisive for financial intermediation volumes, deposit-loan spreads, and the length of the central bank balance sheet.

- In scenario VI, the central responds to the crisis by lowering the width of its standing facilities corridor to 10 basis points. As a consequences, the financial accounts and the deposit-repo spread return to their scenario III values. (Only two items differ in the financial accounts between scenarios III and VI: interbank lending is substituted by two sided recourse of the banking system to the central bank.)

Scenario VI in the previous section illustrated how in a financial crisis in which central bank interbank intermediation is relevant, the width of the corridor has a direct bearing on the stance of monetary policy. Indeed, the wider the corridor, the higher will be the interest rate applied to loans, and the lower will be the total volume of credit granted to the banking system. The effect of the increase of the relevant interbank intermediation spread on loan interest rates can in principle be neutralised either by narrowing the standing facilities corridor, or via a lowering of the overall interest rate level.

Figure 4 illustrates, starting from case III (or VI), how changes in the width of the interest rate corridor affect the total volume of financial intermediation, the extent of double recourse to the central bank (i.e. interbank intermediation through the central bank balance sheet, as measured through the recourse to the central bank deposit facility), and the deposit-loan rate spread.

The charts show that starting from a zero spread, the financial intermediation and the central bank interbank intermediation both decline linearly. These reflect different points of intersection between the aggregate supply and demand curves for financial intermediation which are all located in the third segment of the supply curve. When the width of the central bank corridor reaches 160 basis points, this changes in the sense that no recourse to interbank intermediation takes place any longer, reflecting that the new equilibrium is at an intersection of demand and supply in the second linear segment of the intermediation supply curve. Unsurprisingly, a further widening of the width of the standing facilities corridor makes no difference as the facilities are unattractive anyway. The deposit-corporate loan spread also reflects these two regimes. It first increases linearly with the increase of the width of the standing facilities corridor, and then reaches a plafond at 320 basis points (when the width of the corridor reaches 160 basis points).

It should be noted that over and above such simple numerical examples, the recent crisis provides a good opportunity to investigate the impact of standing facilities corridor on interbank turnover, since it has 
Figure 4: The volume of financial intermediation (left-hand panel) and the spread between the household deposit rate and corporate loan rate (right-hand panel)
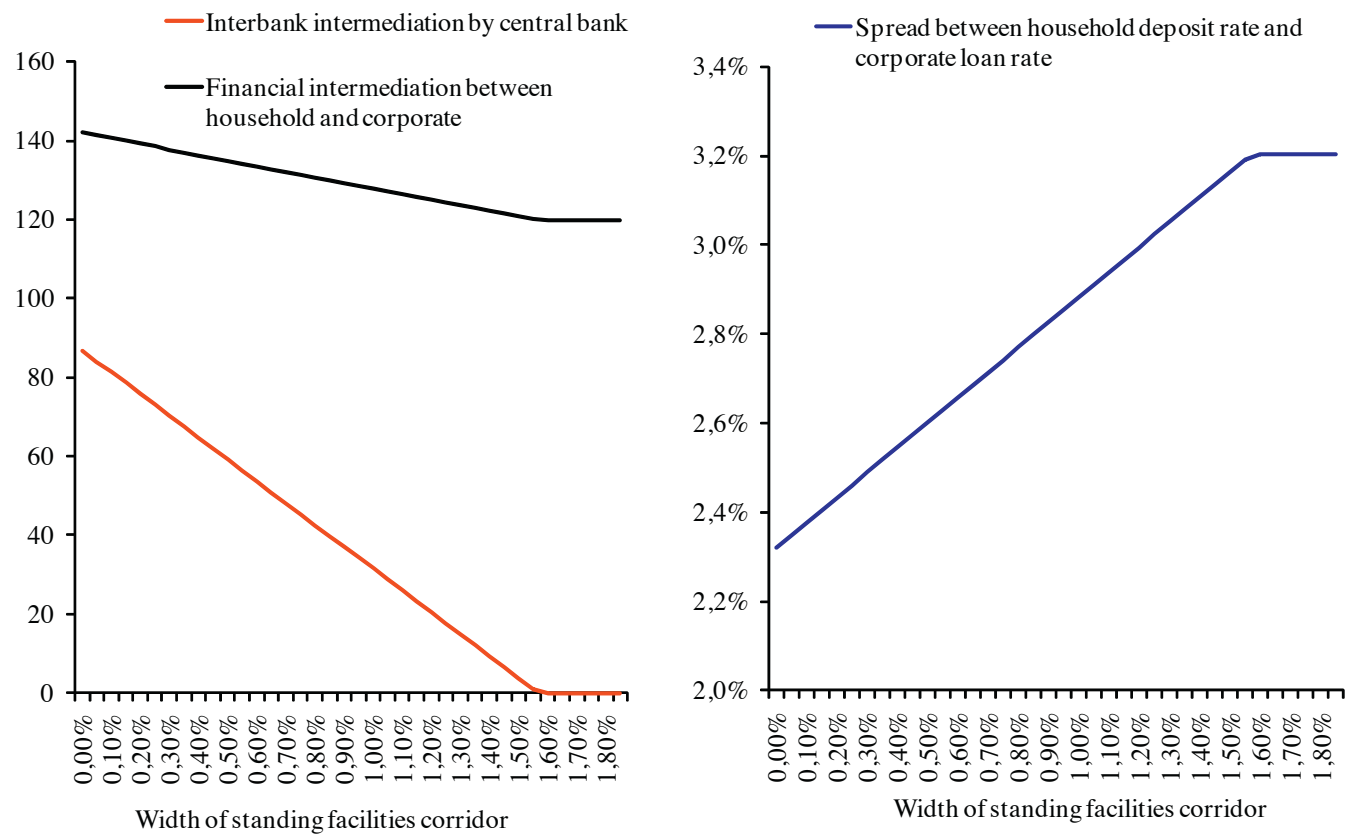

prompted a number of central banks to ease the conditions on which their standing facilities operate (or create such facilities if none had been in place). For example, the ECB and the Hungarian Central Bank (MNB) have both narrowed and then widened their respective corridors over the course of the turmoil. The impact of the latter policies is investigated empirically by Bindseil and Jablecki (2011) who find that in each case there is a strong statistically significant effect of falling turnover in response to a reduction in corridor width. Additionally, turnover correlates negatively with interbank intermediation and a structural break can be identified, with both the slope and intercept changing after the failure of Lehman Brothers in September 2008.

\section{Conclusions}

The current financial crisis suggested that large scale double-sided recourse to central bank standing facilities may occur in a persistent manner over a long period of time, and therefore seems to indicate structural differences between banks and the inability to achieve arbitrage across banks' marginal costs through money market transactions. The structural model presented provides a very simple and relevant intuition for why in a financial crisis, in which both interbank transaction costs increase dramatically (to be prohibitive for many banks), and also differences between banks with regard to outside funding options intensify, a sudden massive central bank intermediation is demanded by the banking system. 
The paper proposes a structural model which captures empirically relevant elements of these trade-offs. The model is based on a closed system of financial accounts with sectors represented including households, corporates, the banking system (represented by two banks) and the central bank. This ensures that the effects of structural differences of competitiveness within the banking system and/or liquidity shocks are reflected comprehensively in the entire financial system, in contrast to partial models in which some effects on the financial system may be missed. Interbank transaction costs are a key determinant of an optimal width of the standing facilities corridor. Indeed, central bank intermediation is in some way a substitute for interbank markets, and therefore the relative level of costs between the two tends to be crucial.

The structural model helps to explain long term two sided recourses to central bank facilities, as they were observed notably in the euro area during the financial turmoil from Fall 2008 to 2010. It also explains why, structurally, some banks are short and some banks are long in the interbank money market. The model captures the interaction between static differences of competitiveness within a heterogeneous banking system and the monetary policy implementation framework, and yields testable predictions on the effects of a financial crisis on interbank market activity and on the length of the central bank balance sheet. In particular, the model allows to explain the reduced interbank volumes and the long-term financial intermediation by the Eurosystem after September 2008, and also why in the first part of the crisis, namely between August 2007 and August 2008, the short term interbank market witnessed an increase in volumes.

In a financial crisis in which interbank markets break down, the model predicts that the narrower the standing facility corridor, (i) the larger will be the central bank intermediation volume; (ii) the lower will be the interbank lending volume; (iii) the higher will be the total intermediation between households and corporates achieved by the financial system, and (iv) the lower will be the interest rates to be paid by corporates for obtaining loans. The latter two also mean that the narrower the corridor, the lower will be the contraction via financial intermediation triggered by a financial crisis. The structural model presented in this paper adds to Berentsen and Monnet (2008) and Cúrdia and Woodford (2010) another powerful link between implementation technique and the stance of monetary policy, and how policy can react to this by using the width of the corridor and/or the length of the central bank balance sheet as an independent policy variable.

\section{Annex 1: Proof of propositions}

\section{Proof of Proposition 1}

The proof will be provided for each segment of the supply curve of bank intermediation services. 


\section{- First segment of the supply curve}

To achieve equality of marginal cost, in view of the marginal cost functions of banking activities of the two banks, the respective size of banking operations of the banks always needs to be inversely proportional to the marginal cost factors: $\frac{D_{1}}{D_{2}}=\frac{k_{2}}{k_{1}} ; \frac{L_{1}}{L_{2}}=\frac{p_{2}}{p_{1}}$ By substitution, one obtains that the common marginal cost functions of the banking system will be:

$$
\begin{gathered}
C^{D}=\frac{k_{1} k_{2}}{k_{1}+k_{2}} D \\
C^{L}=\frac{p_{1} p_{2}}{p_{1}+p_{2}} L=\frac{p_{1} p_{2}}{p_{1}+p_{2}}(D+B)
\end{gathered}
$$

Thus, the total marginal cost of financial intermediation is given by:

$$
C^{T}=C^{D}+C^{L}=\frac{p_{1} p_{2}}{p_{1}+p_{2}} B+\left(\frac{k_{1} k_{2}}{k_{1}+k_{2}}+\frac{p_{1} p_{2}}{p_{1}+p_{2}}\right) D
$$

The first kink point is reached in this case only if $\widehat{C B B_{2}}=B$, i.e. the unconstrained central bank borrowing by Bank 2 reaches the level of banknotes in circulation. We first characterize the first kink point. This is when the banknotes in circulation are "exhausted" as source to equilibrate marginal cost conditions across banks. The "exhaust" point can be translated into $C B B_{2}=B ; C B B_{1}=0$, which implies $L_{1}=D_{1}$ and $D_{2}=L_{2}+B$. At the same time, we know that in this point, still $D_{1}=\frac{k_{2}}{k_{1}+k_{2}} D, D_{2}=\frac{k_{1}}{k_{1}+k_{2}} D, L_{1}=\frac{p_{2}}{p_{1}+p_{2}} L$, and $L_{2}=\frac{p_{1}}{p_{1}+p_{2}} L$. Thus, by substitution we can show that the kink point is uniquely identified as follows

$$
\begin{aligned}
D^{K_{1}} & =\frac{p_{2}\left(k_{1}+k_{2}\right)}{p_{1} k_{2}-p_{2} k_{1}} B \\
L^{K 1} & =\frac{p_{2}\left(k_{1}+k_{2}\right)}{p_{1} k_{2}-p_{2} k_{1}} B+B=\frac{p_{2} k_{2}+p_{1} k_{2}}{p_{1} k_{2}-p_{2} k_{1}} B
\end{aligned}
$$

Note that as it was assumed that it was Bank 2 which had used all the central bank credit available, it must have had comparative advantages in loan provision and comparative disadvantages in deposit collection. Hence, the denominator $p_{1} k_{2}-p_{2} k_{1}$ must be positive. From total amounts, individual amounts can again be calculated by assuming efficient sharing. Total marginal costs will be accordingly:

$$
c^{T, K 1}=\left[\frac{p_{1} p_{2}}{p_{1}+p_{2}} \frac{p_{2} k_{2}+p_{1} k_{2}}{p_{1} k_{2}-p_{2} k_{1}}+\frac{k_{1} k_{2}}{k_{1}+k_{2}} \frac{p_{2}\left(k_{1}+k_{2}\right)}{p_{1} k_{2}-p_{2} k_{1}}\right] B=p_{2} k_{2} \frac{p_{1}+k_{1}}{p_{1} k_{2}-p_{2} k_{1}} B
$$


By definition, after kink point 1 is reached, and before interbank trading kicks in, each banking business needs to grow separately, i.e. for each bank taken separately, deposits and loan volumes must grow in parallel. At the same time, the businesses of the two banks will not grow at an identical speed, but in a way that is inversely proportional to their respective total marginal cost, such that their marginal total cost stay identical, thereby minimizing social marginal costs (total marginal costs of the banking system). In analogy to the derivation of the common marginal cost function of the banking system in the first segment, the total marginal costs of the banking system are

$$
c^{T, K 1 \rightarrow K 2}=c^{T, K 1}+\frac{\left(k_{1}+p_{1}\right)\left(k_{2}+p_{2}\right)}{k_{1}+k_{2}+p_{1}+p_{2}}\left(D-D^{K 1}\right)
$$

This continues over the second linear segment of the supply curve, until the point is reached in which interbank trading kicks in. Interbank trading kicks in when the gross gains from interbank trading exceed interbank intermediation transaction costs. One can think of the interbank transaction being used to re-allocate deposit collection activity from Bank 2 to Bank 1 (as marginal costs in the abovedescribed efficient pre-interbank market sharing of intermediation are higher in deposit collection for Bank 2). The marginal gross gain from such a shift in deposit collection can be calculated as follows. We know that in the segment linear segment of the total marginal cost curves, the growth in banking business must be subdivided between the two banks as follows:

$$
\begin{aligned}
& \Delta D_{1}=\frac{k_{2}+p_{2}}{k_{1}+k_{2}+p_{1}+p_{2}} \Delta D \\
& \Delta D_{2}=\frac{k_{1}+p_{1}}{k_{1}+k_{2}+p_{1}+p_{2}} \Delta D
\end{aligned}
$$

We also know that the difference between marginal costs of deposit collection will be $k_{1} \Delta D_{1}-k_{2} \Delta D_{2}$. By substitution, we obtain the following equation which will allow us to identify $D_{1}^{K 2}$

$$
\begin{gathered}
\left(k_{1} \frac{k_{2}+p_{2}}{k_{1}+k_{2}+p_{1}+p_{2}}-k_{2} \frac{k_{1}+p_{1}}{k_{1}+k_{2}+p_{1}+p_{2}}\right) \Delta D=u \\
\Leftrightarrow D^{K 2}=D^{K 1}+\frac{u}{\left(k_{1} \frac{k_{2}+p_{2}}{k_{1}+k_{2}+p_{1}+p_{2}}-k_{2} \frac{k_{1}+p_{1}}{k_{1}+k_{2}+p_{1}+p_{2}}\right)}=D^{K 1}+u \frac{k_{1}+p_{1}+k_{2}+p_{2}}{k_{2} p_{1}-k_{1} p_{2}}
\end{gathered}
$$

By substitution into the marginal cost function prevailing in the second segment:

$$
c^{T, K 2}=c^{T, K 1}+\frac{\left(k_{1}+p_{1}\right)\left(k_{2}+p_{2}\right)}{k_{1}+k_{2}+p_{1}+p_{2}} u \frac{k_{1}+p_{1}+k_{2}+p_{2}}{k_{2} p_{1}-k_{1} p_{2}}=c^{T, K 1}+u \frac{\left(k_{1}+p_{1}\right)\left(k_{2}+p_{2}\right)}{k_{2} p_{1}-k_{1} p_{2}}
$$




\section{- Third linear segment of the supply curve}

The increase of deposits and of loans will be split up each into sub-components in a way that the marginal cost differences on both sides of activities remain the same across banks - namely equal to transaction costs. Denote by $\Delta D(=\Delta L)$ the change of deposit (loan) volume beyond the level in which interbank trading has kicked in, i.e. $\Delta D=D-D^{K 2}$. First, we need to split $\Delta D$ between Bank 1 and Bank 2, $\alpha$ being the share of Bank 1, such that the difference between the marginal costs of deposit collection stay the same across banks, namele equal $u$, and $k_{1} \alpha \Delta D=k_{2}(1-\alpha) \Delta D$, which implies $\alpha=\frac{k_{2}}{k_{1}+k_{2}}$. Second, we need to split up $\Delta L(=\Delta D)$ between Bank 1 and Bank $2, \beta$ being the share of Bank 1, so that the difference between marginal costs of loan provision stay the same across banks, namely equal to $u$ ? Reasoning as before, we obtain $\beta=\frac{p_{2}}{p_{1}+p_{2}}$. Interbank lending from Bank 1 to Bank 2 will be equal to: $\alpha-\beta$ per unit of expansion of intermediation beyond kink point 2 . Therefore,

$$
Y=\left(D-D^{K 2}\right)(\alpha-\beta)=\left(D-D^{K 2}\right)\left[\frac{k_{2}}{k_{1}+k_{2}}-\frac{p_{2}}{p_{1}+p_{2}}\right]
$$

Total increases of marginal costs of the two activities of the entire banking system will now again correspond to the increases of marginal cost in segment 1 . Therefore, total marginal costs of the banking system beyond the kink point will be:

$$
c^{T, K 2 \rightarrow \infty}=c^{T, 2}+\left(D-D^{K 2}\right)\left[\frac{k_{1} k_{2}}{k_{1}+k_{2}}+\frac{p_{1} p_{2}}{p_{1}+p_{2}}\right]
$$

\section{Proof of Proposition 2}

First we derive the demand schedule for intermediation services. The marginal opportunity cost of depositing with banks is: $i^{M V, D}=\frac{D}{b}$. The marginal valuation of loans to the corporate is $i^{M V, L}=\frac{R-L}{d}=$ $\left.\frac{1}{d}(R-B-D)\right)$. Hence the demand schedule $q(D)=i^{M V, L}-i^{M V, D}=\frac{R-B}{d}-\frac{b+d}{b d} D$ Second, since $q(D)$ is a monotonously declining function with $D(0)>0$ and $c^{T}(D)$ is monotonously increasing according to Proposition 1 with $c^{T}(0)=0$. From the equilibrium value of $D *$ follows $L *=D *+B$. total net central bank borrowing is equal to banknotes, as implied by the central bank balance sheet identity: $B=C B B_{1}+$ $C B B_{2}-C B D_{1}-C B D_{2}$. The disaggregation of the total deposit and loan amounts has to be done one by one for each of the three segments of the intermediation supply schedule. If the intersection is not in segment 3 of the intermediation supply schedule, but in segment 1 or 2 , then only the relevant segments need to be considered. 


\section{- First linear segment of the supply curve}

At $D=0$ and $L=B$, and assuming that Bank 1 is the bank with comparative advantages in deposit collection, the following sharing of the recourse to central bank operations and of loan provision will prevail: $C B B_{1}=L_{1}=\frac{p_{2}}{p_{1}+p_{2}} B ; C B B_{2}=L_{2}=\frac{p_{1}}{p_{1}+p_{2}} B$. It can be easily verified that this ensures $c_{1}^{L}=c_{2}^{L}$, and hence one cannot reduce total aggregate cost of loan provision through a re-allocation at the margin between the two banks. From $D=0$, in view of the marginal cost functions of banking activities of the two banks, the expansion of banking operations with growing volumes of deposits always needs to be inversely proportional to the marginal cost factors such as to preserve equality of marginal costs across banks on both balance sheet sizes: $\frac{D_{1}}{D_{2}}=\frac{k_{2}}{k_{1}} ; \frac{L_{1}}{L_{2}}=\frac{p_{2}}{p_{1}}$ The wedge between the two banks' central bank borrowing volumes will increase continuously, and at kink point 1 the bank with a comparative advantage in deposit collection will have no longer any recourse to central bank borrowing. Hence: $C B B_{1}^{K 1}=0 ; C B B_{2}^{K 1}=B ; D_{1}^{K 1}=\frac{k_{2}}{k_{1}+k_{2}} D^{K 1} ; D_{2}^{K 1}=\frac{k_{1}}{k_{1}+k_{2}} D^{K 1} ; L_{1}^{K 1}=D_{1}^{K 1}$; $L_{2}^{K 1}=D_{2}^{K 1}+B$.

\section{- Second linear segment of the supply curve}

As shown in the proof of Proposition 1, $\Delta D_{1}=\frac{k_{2}+p_{2}}{k_{1}+k_{2}+p_{1}+p_{2}} \Delta D$ and $\Delta D_{2}=\frac{k_{2}+p_{1}}{k_{1}+k_{2}+p_{1}+p_{2}} \Delta D$. Moreover, as no interbank intermediation prevails in this segment, $\Delta L_{1}=\Delta D_{1}$ and $\Delta L_{2}=\Delta D_{2}$.

\section{- Third linear segment of the supply curve}

In line with values of $\alpha$ and $\beta$ derived in Proposition 1, one obtains $\Delta D_{1}=\frac{k_{2}}{k_{1}+k_{2}} \Delta D$ and $\Delta D_{2}=$ $\frac{k_{1}}{k_{1}+k_{2}} \Delta D, \Delta L_{1}=\frac{p_{2}}{p_{1}+p_{2}} \Delta D$ and $\Delta L_{2}=\frac{p_{1}}{p_{1}+p_{2}} \Delta D$ (noting that $\Delta D=\Delta L$ ). Interbank intermediation takes place either through interbank market or throught the central bank, whereby the relative size of interbank transaction cost $u$ and $v$ determine which one is positive. If $u<v$, then $C B D=0$ and $Y=\left(D-D^{K 2}\right)\left[\frac{k_{2}}{k_{1}+k_{2}}-\frac{p_{2}}{p_{1}+p_{2}}\right]$. If instead $u>v$, then reverse values prevail. If $u=v$, then the splitup of interbank intermediation between the two markets is indeterminate (in the examples we assume that still the interbank market would be used). 


\section{Annex 2: Details of the intermediation supply schedule}

Table 7: Details of the intermediation supply schedule presented in Table 6

\begin{tabular}{|c|c|c|c|c|c|c|}
\hline Scenario & I & II & III & IV & $\mathrm{V}$ & VI \\
\hline HH equity $E$ & 500 & 500 & 500 & 500 & 500 & 500 \\
\hline Banknote demand $B$ & 100 & 100 & 100 & 100 & 100 & 100 \\
\hline HH preference parameter $b$ & 5000 & 5000 & 5000 & 5000 & 5000 & 5000 \\
\hline Corporate technology paramater $R$ & 500 & 500 & 500 & 500 & 500 & 500 \\
\hline Corporate technology paramater $d$ & 5000 & 5000 & 5000 & 5000 & 5000 & 5000 \\
\hline marg cost depo coll B1 $k_{1}$ & $0,010 \%$ & $0,010 \%$ & $0,010 \%$ & $0,010 \%$ & $0,010 \%$ & $0,010 \%$ \\
\hline marg cost depo coll B2 $k_{2}$ & $0,010 \%$ & $0,010 \%$ & $0,200 \%$ & $0,010 \%$ & $0,200 \%$ & $0,200 \%$ \\
\hline marg cost loan prov B1 $p_{1}$ & $0,020 \%$ & $0,010 \%$ & $0,020 \%$ & $0,020 \%$ & $0,020 \%$ & $0,020 \%$ \\
\hline marg cost loan prov B2 $p_{2}$ & $0,005 \%$ & $0,005 \%$ & $0,005 \%$ & $0,005 \%$ & $0,005 \%$ & $0,005 \%$ \\
\hline Interbank TAC $u$ & $0,10 \%$ & $0,10 \%$ & $0,10 \%$ & $3,00 \%$ & $3,00 \%$ & $3,00 \%$ \\
\hline Width of corridor $w$ & $2,00 \%$ & $2,00 \%$ & $2,00 \%$ & $2,00 \%$ & $2,00 \%$ & $0,10 \%$ \\
\hline \multicolumn{7}{|c|}{ Characteristics of the intermediation supply curve } \\
\hline total $\mathrm{MC}$ at $D=0$ & 0,004 & 0,003 & 0,004 & 0,004 & 0,004 & 0,004 \\
\hline delta $\mathrm{MC} D=0 \rightarrow K 1$ & $0,009 \%$ & $0,008 \%$ & $0,014 \%$ & $0,009 \%$ & $0,014 \%$ & $0,014 \%$ \\
\hline$D$ at $K 1$ & 66,67 & 200,00 & 26,58 & 66,67 & 26,58 & 26,58 \\
\hline$M C$ at $K 1$ & 0,01 & 0,02 & 0,0076 & 0,01 & 0,0076 & 0,0076 \\
\hline$\triangle M C D=K 1 \rightarrow K 2$ & $0,010 \%$ & $0,009 \%$ & $0,026 \%$ & $0,010 \%$ & $0,026 \%$ & $0,026 \%$ \\
\hline$D_{1}$ share $0 \rightarrow K 1$ & 0,500 & 0,500 & 0,952 & 0,500 & 0,952 & 0,952 \\
\hline$D_{2}$ share $0 \rightarrow K 1$ & 0,500 & 0,500 & 0,048 & 0,500 & 0,048 & 0,048 \\
\hline$L_{1}$ share $0 \rightarrow K 1$ & 0,200 & 0,333 & 0,200 & 0,200 & 0,200 & 0,200 \\
\hline$L_{2}$ share $0 \rightarrow K 1$ & 0,800 & 0,667 & 0,800 & 0,800 & 0,800 & 0,800 \\
\hline$D$ at $K 2$ & 96,67 & 270,00 & 32,53 & 666,67 & 145,57 & 32,53 \\
\hline$M C$ at $K 2$ & 0,013 & 0,026 & 0,0092 & 0,07 & 0,0387 & 0,0092 \\
\hline$\triangle M C D=K 2 \rightarrow \infty$ & $0,009 \%$ & $0,008 \%$ & $0,014 \%$ & $0,009 \%$ & $0,014 \%$ & $0,014 \%$ \\
\hline$D_{1}$ share $K 1 \rightarrow K 2$ & 0,333 & 0,429 & 0,872 & 0,333 & 0,872 & 0,872 \\
\hline$D_{1}$ share $K 1 \rightarrow K 2$ & 0,667 & 0,571 & 0,128 & 0,667 & 0,128 & 0,128 \\
\hline$D_{2}$ share $K 1 \rightarrow K 2$ & 0,333 & 0,429 & 0,872 & 0,333 & 0,872 & 0,872 \\
\hline$L_{1}$ share $K 1 \rightarrow K 2$ & 0,667 & 0,571 & 0,128 & 0,667 & 0,128 & 0,128 \\
\hline$L_{2}$ share post $K 2$ & 0,500 & 0,500 & 0,952 & 0,500 & 0,952 & 0,952 \\
\hline$D_{2}$ share post $K 2$ & 0,500 & 0,500 & 0,048 & 0,500 & 0,048 & 0,048 \\
\hline$L_{1}$ share post $K 2$ & 0,200 & 0,333 & 0,200 & 0,200 & 0,200 & 0,200 \\
\hline$L_{2}$ share post $K 2$ & 0,800 & 0,667 & 0,800 & 0,800 & 0,800 & 0,800 \\
\hline Gross marginal rent in $D=0$ & 0,080 & 0,080 & 0,080 & 0,080 & 0,080 & 0,080 \\
\hline Gross marginal rent Int $K 1$ & 0,053 & 0,000 & 0,069 & 0,053 & 0,069 & 0,069 \\
\hline Gross marginal rent Int $K 2$ & 0,041 & $-0,028$ & 0,067 & $-0,187$ & 0,022 & 0,067 \\
\hline delta of gros marg rent & $-0,0004$ & $-0,0004$ & $-0,0004$ & $-0,0004$ & $-0,0004$ & $-0,0004$ \\
\hline
\end{tabular}




\section{References}

Allen, F., And D. Gale (2000): "Financial Contagion," Journal of Political Economy, 108(1), 1-33.

Angelini, P., A. Nobili, And M. C. Picillo (2009): "The interbank market after August 2007: what has changed, and why?," Temi di discussione (Economic working papers) 731, Bank of Italy, Economic Research Department.

Berentsen, A., A. Marchesiani, and C. J. Waller (2010): "Channel systems: why is there a positive spread?," IEW - Working Papers 517, Institute for Empirical Research in Economics - IEW.

Berentsen, A., And C. Monnet (2008): "Monetary policy in a channel system," Journal of Monetary Economics, 55(6), 1067 - 1080.

Bindseil, U. (2004): Monetary Policy Implementation. Theory, Past, and Present. New York: Oxford University Press. Oxford University Press.

Bindseil, U., AND J. JABLECKI (2011): "The optimal width of the standing facilities corridor and bank liquidity management," forthcoming in WPS.

Bindseil, U., And F. PAPAdia (2007): "Risk management and market impact of central bank credit operations," in Risk management for central bank and other public investors, ed. by U. Bindseil, F. Gonzalez, and E. Tabakis, pp. 271-302. Oxford University Press.

Cúrdia, V., And M. Woodford (2010): "Conventional and Unconventional Monetary Policy," Federal Reserve Bank of St. Louis Review, 92(4), 229-64.

Freixas, X., B. M. Parigi, and J.-C. Rochet (2000): "Systemic Risk, Interbank Relations, and Liquidity Provision by the Central Bank," Journal of Money, Credit and Banking, 32(3), 611-638.

Furfine, C. H. (2001): "Banks as Monitors of Other Banks: Evidence from the Overnight Federal Funds Market," Journal of Business, 74(1), 33-57.

Heinle, E., And M. Koivu (2009): "Risk measurement for a repo portfolio - an application to the Eurosystem's collateralized lending operations," in Risk management for central bank and other public investors, ed. by U. Bindseil, F. Gonzalez, and E. Tabakis, pp. 359-392. Oxford University Press.

Hoerova, M., And C. Monnet (2010): "Central Bank Lending and Money Market Discipline," Unpublished manuscript.

KING, T. B. (2008): "Discipline and Liquidity in the Interbank Market," Journal of Money, Credit and Banking, 40(2-3), 295-317. 
Rochet, J.-C., And J. Tirole (1996): "Interbank Lending and Systemic Risk," Journal of Money, Credit and Banking, 28(4), 733-62.

Whitesell, W. (2006): "Interest rate corridors and reserves," Journal of Monetary Economics, 53(6), $1177-1195$.

Wiseman, J. D. (2007): "The pretend market for money," Central Banking.

Woodford, M. (2003): Interest and Prices: Foundations of a Theory of Monetary Policy. Princeton University Press. 
